\title{
Generating Electricity through Harnessing of Kinetic Energy Using a Ramp
}

\author{
Tehseen Ilahi, Adnan Afroz, Muhammad Umar Khan, Arsalan Zafar, Khusro Bakht, and Shoaib Altaf
}

\begin{abstract}
This energy ramp is an extensive approach in the field of alternativerenewableenergy. It is a mechanismtoproduce electricity by harnessing the kinetic energy of vehicles that drives over the ramp. The objective is to design a system that decreases the energy crisis in Pakistan by utilizing the vehicles kinetic energy. The system can be implemented just before or just after the entrance of e.g. Tool Plazas, Hospitals, U-turns, Airports etc.
\end{abstract}

Index Terms-Alternative energy, electricity, energy ramp, kinetic energy

\section{INTRODUCTION}

Mr. Hughes developed the idea of producing energy from speed breaker over the past 12 years [1]. An experiment had been conducted in the parking lot of Sainsbury grocery store in June 2009 by setting up a device to get sufficient amount of energy for operating the cash registry all over the store. When a car passes over the ramp, the ramp gets pressed, activating an alternator that charges an accumulator. The prototype was created \& tested at Hughes Research unit at the Westland Helicopter base in Somerset, at a cost of $£ 1$ million.

The large amount of energy is wasted through speed breaker.There is great possibility of tapping this energy and generating power by making the speed-breaker [2]

This ramp is not like usual speed breakers. It is not harmful for the vehicles or cannot become the cause of waste petrol when a carpasses over it. The speed ramp is not dangerous for vehicles at all. It does not only generate free energy, but the energy that has been generated is environment friendly with almost no pollution. One has to pay the capital cost for the whole system, and then it is free.

The trick is collecting that energy \& distributing it in a cost-effective way. We are creating a new industry $\&$ if we are first to market with this thing we definitely will be at the top of the wave.

The electricity produced from ramp is said to be "clean" because its production produces no pollution. As both health and environmental concerns are on the rise, clean

Manuscript received April 9, 2013; revised July 25, 2013.

T. Ilahi is with Energy Engineering, University of Engineering and Technology, Lahore, Pakistan (e-mail: engineer_tehseen@yahoo.com).

A. A frozand M. U. Khan are with Telecommunication Engineering Department, Sir Syed University of Engineering \& Technology, Karachi, Pakistan (e-mail: adnaaf@hotmail.com;m_umar_k@hotmail.com).

A. Zafar is with the Pronet Pvt. Ltd, Pakistan (e-mail: arsalanzafar44@hotmail.com).

K. Bakhtis is with Alcon Scientific Services, Lahore, Pakistan (e-mail: Shoaib.led@gmail.com)

S. Altafis is with Standard Engineering Company, Karachi, Pakistank (e-mail:husro456@hotmail.com) energy sources are a growing demand. [3] We are proud to present the energy ramp which is made to deploy on roads and that can produce electrical energy with out any cost when a vehicle passes over it.

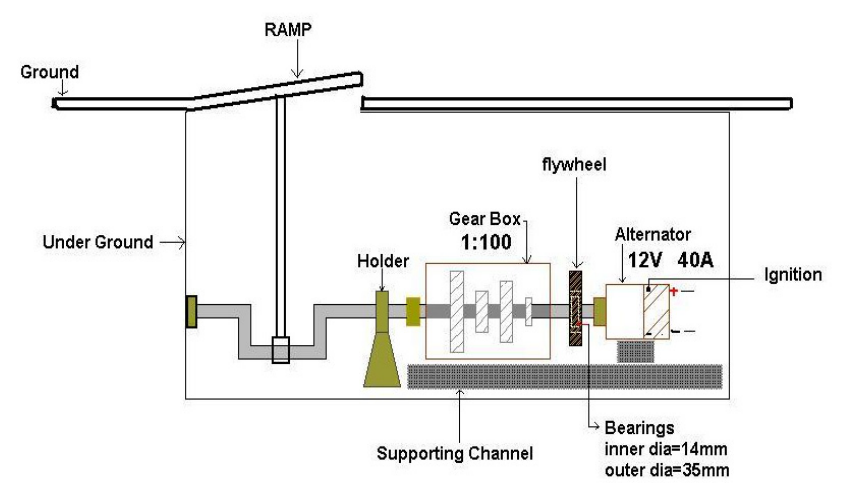

Fig. 1. Energy ramp structure

\section{SYSTEM MODEL}

On the whole, the overall Energy Ramp system is a combination of both software as well as hardware model. The information given below will describe the features of both the models.

\section{A. Hardware Model}

The hardware model consists of a slab that is press down by the vehicle. When it is passes over slab translation motion produce[4]. The crank is attachedto a system which contains Gearbox, Flywheel \& Alternator.

For the storing purpose, a Battery is attached to the Alternator. Inverter is place with the Battery and a Load Bank is also attached.

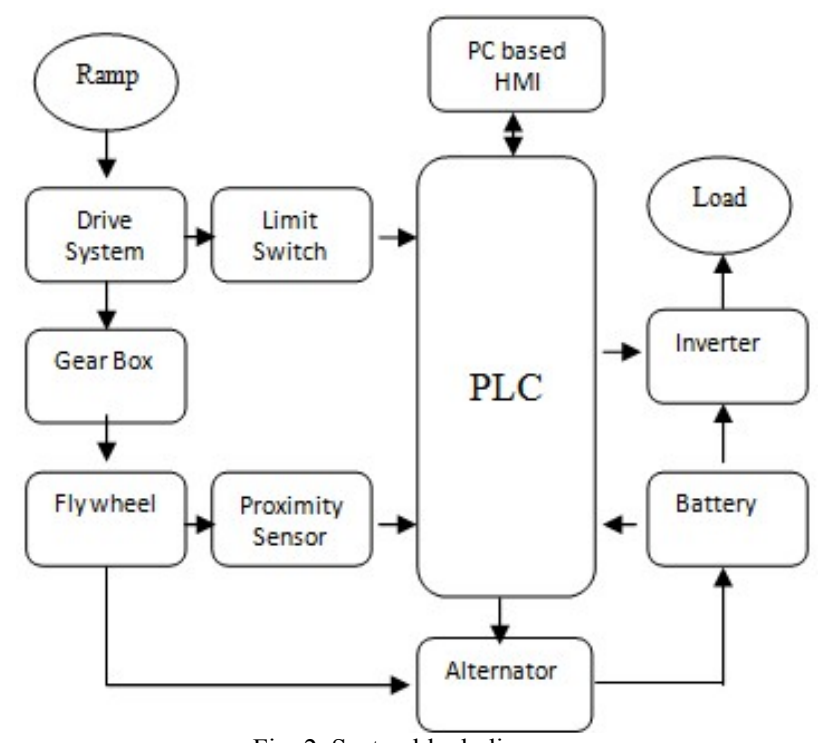

Fig. 2. Systemblock diagram 
A rotation reader circuit is placed in front of Flywheel. Relays are attached for the purpose of controlling. First one is attached between Alternator \& Battery and second is between Battery and Inverter that break the connection. The third relay is placed between the inverter and the load which indicates the completion of process i.e. when inverter passes $220 \mathrm{~V}$ it energies the relay and a connection is produced between the Inverter and the Load Bank.

A Limit switch is placed below the slab for the counting of the cars. When a car passes over the slab, the limit switch is pressed then the limit switch signals sends to the digital input (1746-IB16) module.

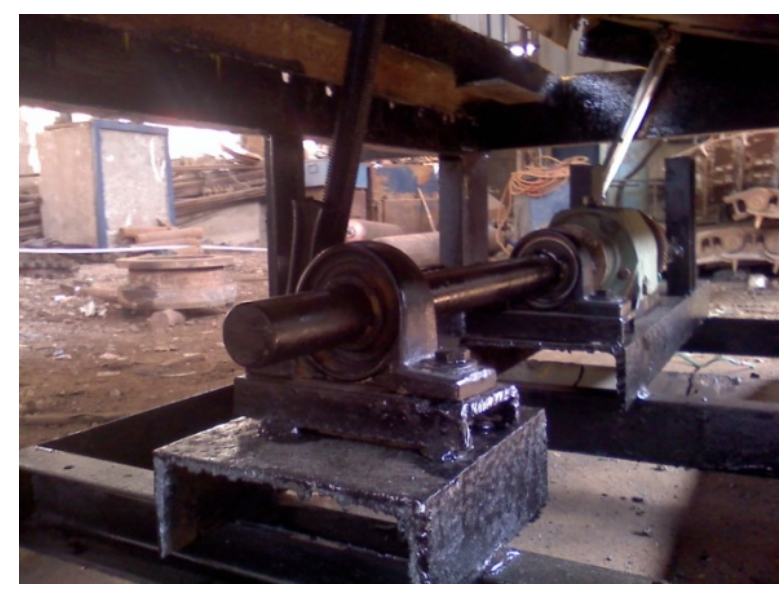

Fig. 3. Internal hardware arrangement

\section{B. Software Model}

Allen Bradley SLC 5/03 PLC is used for monitoring \& controlling of the system[5] and a PC-Based HMI is connected with it for displaying the process.

Whole system is fully automated with programmable logic controller PLC.

The Software's that are used for Automation are listed below:

$$
\begin{array}{ll}
\text { R SLinx Classic } & \text { : Diver installer } \\
\text { RSLogix } 500 & \text { : Ladder Programmer }
\end{array}
$$

R SLogix Emulate 500 : Offline Simulator.

$$
\text { R SV iew } 32 \text { : PC-Based HMI Display }
$$

The Modules that are used in SLC 5/03 are listed below: 1747-L532 (SLC 5/03 Processor)

1746-IB16 (Digital dc Input Modules)

1746-OB16 (Digital dc Output Modules)

1746-NI4 (Analog Input Modules)

The rotation reader provided pulses that are the digital input of the 1746-IB16 module. PLC is programmed that the pulses is converted into rpm and are displayed on the PC-Based HMI.

When a car passes over the slab, thelimitswitch is pressed thenthe limit switch signals sends to the digital input (1746IB16) module of PLC. Finally number of cars displayed on the PC-Based HMI.

Relays are attached for the purpose of controlling. The output module (1746-OB16) of PLC controls the relaysandthe indication is displayed in the circuit.

\section{PROCESS DIAGRAM}

This section represents the system process block diagram.

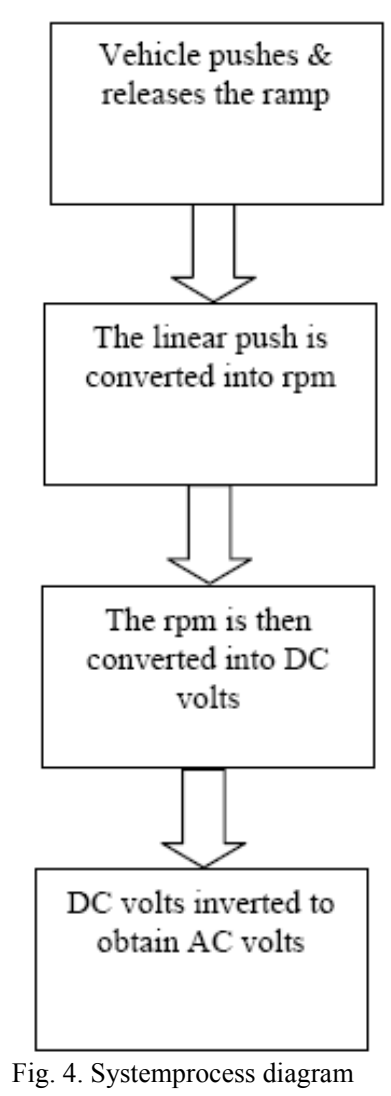

\section{REsult AND Discussion}

When one vehicle passes over the ramp, it produces 12 14 volts \& 8-10 amperes for $2 \times 4$ seconds

- One car produce $12-14 \mathrm{v}$ and $9 \mathrm{~A}$ in 2 seconds

- One car produce Power of 240W. (vehicle pushes twice a slab).

- $500 \mathrm{~W} 43 \mathrm{AH}$ battery will charge in 4 hours.

The hour's calculation is determined by:

Hours $=\mathrm{AH}$ rating/ load current

where Hours is the life of battery. AH rating is the Ampere Hour rating of battery [6].

110watts bulb glow for 4 hour \& 30 minutes

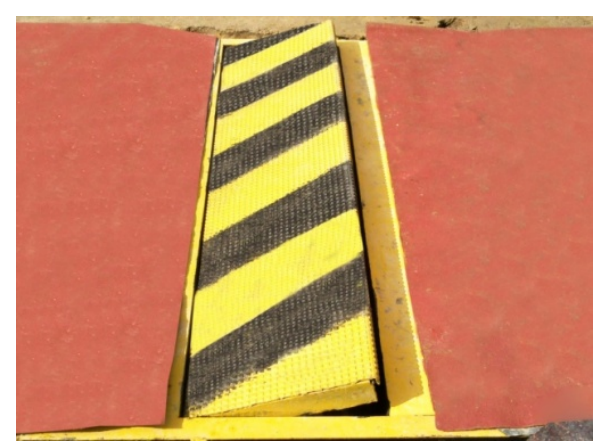

Fig. 5. System implemented at ground

The power is calculated by:

$$
\mathrm{P}=\mathrm{VI}
$$

where $P$ is the power, $\mathrm{V}$ is voltage, and $\mathrm{I}$ is the current.

Hence $\mathrm{I}=\mathrm{P} / \mathrm{V}=110 / 12=9.1$

Therefore,

$$
\begin{aligned}
& \qquad \mathrm{AH}=4.5 \times 9.1 \approx 41 \mathrm{AH} \\
& \text { Kinetic Energy: } \\
& \text { K.E produce in flywheel, } \mathrm{E} \text { (rotational) }=1 / 2 \mathrm{I} \omega 2
\end{aligned}
$$


where $\omega$ is the angular speed

I am the moment of inertia around the axis of rotation. E is the kinetic energy.[7]

Angular speed:

RPM produced in Flywheel is 900 which means

$$
\begin{gathered}
\omega=94.2 \mathrm{rad} / \mathrm{s} \\
\mathrm{I}=\mathrm{mr} 2
\end{gathered}
$$

$\mathrm{M}=$ mass of flywheel $(3 \mathrm{~kg})$

$r=$ radius of flywheel (8inch)

$\mathrm{I}=(3 \mathrm{~kg})(0.08 \mathrm{~m}) 2 \approx 0.02 \mathrm{~kg} \mathrm{~m} 2$

Input $=$ K.E $=1 / 2(0.02)(94.2) 2=88 \mathrm{~J}$

Electrical Energy :

$$
\begin{array}{cc}
\text { Voltage } & =12 \sim 14 \mathrm{~V} \\
\text { Current } & =8 \sim 9 \mathrm{~A} \\
\text { Power }=\mathrm{V} \times \mathrm{I}= & 96 \sim 126 \mathrm{~W}
\end{array}
$$

Work $=$ power time (peak power is generated for $1 / 2 \mathrm{~s})$

$$
\begin{gathered}
=126 \times 0.5=63 \mathrm{~J} \\
\text { Output }=63 \mathrm{~J}
\end{gathered}
$$

Efficiency

$$
\begin{gathered}
\eta \%=(\text { output } / \text { input }) \times 100 \\
=(63 / 88) \times 100 \\
=71.15 \%
\end{gathered}
$$

\section{FUTURE ENHANCEMENT}

In future, we can increase the efficiency of this system by following ways:

- If we use more than one crank in the system, we can drive more alternators.

- The crank can be design in such a way that it gives more rotation per push.

- By using more effective alternators and inverters, we can get less Power losses.

- For costeffectiveness,microcontroller can replace the control unit.

\section{CONCLUSION}

It has been analyzed that currently alternate energy produces approximately $11 \%$ to our primary energy. Also it has been determined that by using coal, oil and gas sources at the current rate,maycause the global temperature raised by 2 degrees Celsius by the year 2020. For this reason, it is assumed that by the year $2070,60 \%$ of the total energy will be generated from alternate energy sources. Deploying such changes earlier may approach these results to $80 \%$.

Now $5 \%$ yearly increase in the use of energy produce by fuel, and cause increase in pollution level and related disasters[9]

Our energy ramp which is the combination of both mechanical and electrical circuitry is an innovative approach in order to decrease the energy crisis globally and to take a step forward to achieve better results.

\section{REFERENCES}

[1] BBC News.

[Online]. Available: http://news.bbc.co.uk/2/hi/uk_news/england/somerset/4535408.stm.

[2] V. Aswathaman and V. Priyadharshini "Every speed breaker is now a source of power," in Proc. of 2010 International Conference on
Biology, Environment and Chemistry IPCBEE, vol. 1, Singapore, 2011.

[3] Techno-Preneur. [Online]. Available: http://www.technopreneur.net/technology/tech-trends/Machines/generating.htm

[4] M. Partodezfoli, "A novel speed-breaker for electrical energy generation suitable for elimination of remote parts of power systems where is near to roads," Journal of Basic and Applied ScienFtific Research, pp. 2090-4304, 2012.

[5] L. A. Bryan, Programmable Controllers Theory and Implementation, 2nd edition, published by Industrial Text Company, USA, 1997.

[6] T. F. Bogart, Electronic Devices and Circuits, in edition 6th, UK, published, 2003.

[7] D. H. Young, Sears and Zemansky'sUniversity physics with modern physics, 12 edition., India, published 2009

[8] B. L. Theraja, Electrical technology, published,India,2010

[9] P. S. Dabrase, "Integrated renewable energy system -perspectives and issues," in Proc. of International Conference on Renewable Energy Technologies IIT, Chennai, 2000.

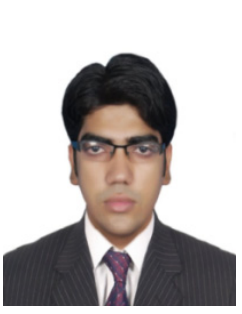

Tehseen Ilahi was born in $25^{\text {th }}$ Dec, 1988 at Karachi, Pakistan. He has done B. S electronics engineering from Sir Syed University of Engineering and Technology, Karachi, Pakistan, in the field of electronics and telecommunication, in 2010. Now, he is doing msc energy engineering from University of Engineering and Technology, UET, KSK Campus, Lahore. He is also a lecturer of cum lab engineer in Department of electrical engineering, Sharif college of engineering \& technology affiliated with UET, Lahore, Pakistan

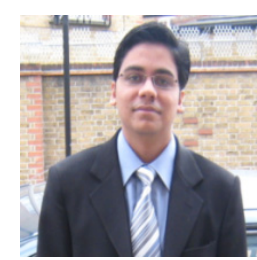

Adnan Afrozhad was working as an assistant professor in telecommunication engineering Department, Sir Syed University of Engineering \& Technology, Karachi, Pakistan since November, 2007. He had done his MSc in telecommunication and computer network engineering from London South Bank University UK. He had also completed his BS in Computer Engineering from Sir Syed University, Pakistan

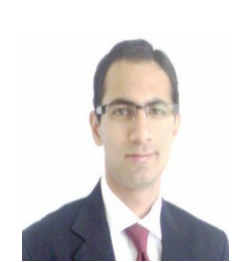

Muhammad Umar Khan had been a lecturer in Sir Syed Engineering University of engineering and technology, Karachi, Pakistan since 2010, at the department of telecommunication engineering. He had completed his MS in electrical engineering with majors in telecommunication from Blekinge $\mathrm{T}$ ekniska Hogskola, Sweden. He has a research interest in the field of WSN, Renewable Power Energy Fiber Optics.

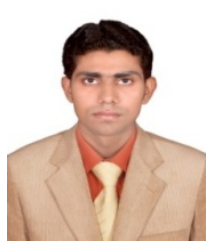

Arsalan Zafar was born in 19th Aug, 1988, Karachi. He had Completed B. S electronics engineering from Sir Syed University of Engineering and Technology, Karachi, Pakistan in the field of electronics and telecommunication in 2010. He has been working as a Senior Support Engineer at Pronet Pvt. Ltd, Pakistan in the field of VoIP Telephony since 2011.

Shoaib Altaf was born in 23 march, 1986 Harripur, Pakistan. He Completedhis B. S electronics engineering From Sir Syed University of Engineering and Technology, Karachi, Pakistan in the field of Electronics and Telecommunication in 2010. Now, he is a MSR instrumentation engineer at Alcon scientific services, Lahore, Pakistan.

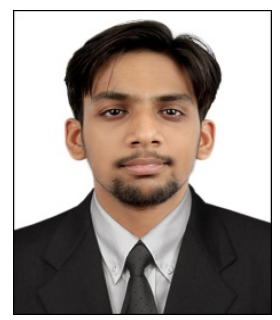

Khusro Bakht was born in $7^{\text {th }}$ April, 1989 at Karachi, Pakistan. He completed B.S electronics engineering From Sir Syed University of Engineering and Technology, Karachi, Pakistan in the field of Electronics and Telecommunication in 2010. He has been working as an assistant project manager at Standard Engineering Company, Karachi, Pakistan, since July 12, 2012. 